Revista Iberoamericana, Vol. LXXIV, Núm. 223, Abril-Junio 2008, 441-454

\title{
LA EMERGENCIA DE MEDELLÍN: LA COMPLEJIDAD, LA VIOLENCIA Y LA DIFFÉRANCE EN ROSARIO TIJERAS Y LA VIRGEN DE LOS SICARIOS ${ }^{1}$
}

POR

Nicholas T. GoOdBody

Yale University

INTRODUCCIÓN:

LA NOVELA SICARESCA Y LA COMPLEJIDAD

La novela sicaresca tiene sus raíces en el crecimiento violento de la ciudad de Medellín. Hay quienes citan la película de Víctor Gaviria, Rodrigo D. No futuro (1989) y el documentalficción de Alonso Salazar No nacimos pa'semilla (1990) como antecedentes de este género literario (Walde 224), mientras otros mantienen que nació con la publicación de novelas como El divino de Gustavo Álvarez Gardeazábal (1986) (Cardona López 383). El término mismo fue inventado por el novelista colombiano Héctor Abad Faciolince, quien, irónicamente, se negaba a incluir cualquier tipo de violencia en sus obras (Lander 87). Variación mordaz del término "picaresca”, la sicaresca se concentra en una nueva y más extrema versión del pícaro: el sicario, un joven asesino de los barrios pobres de Medellín que trabaja en los márgenes más violentos del narcotráfico. Quizás sea por causa del carácter vívido y agobiante de la delincuencia que rodea a este personaje, que las investigaciones sobre la novela sicaresca suelen abordar el género usando la violencia como punto de partida e idea central. Se observa en ella una violencia sin causas ni consecuencias claras, que no se puede hacer inteligible (Cabañas 8; Walde 223), y se la interpreta como una crítica de la fragmentación de la identidad colombiana, un ejemplo del fracaso de los ideales modernos de identidad nacional, historia global y posibilidad para la raza humana de superar su propio lado oscuro (Fernández L’Hoeste 778; Lander 76). Sin embargo, tales interpretaciones a veces pierden de vista el papel central que juega el propio Medellín en estas obras. La ciudad no es meramente un trasfondo para la sicaresca del cual podemos extraer y analizar una noción abstracta de la violencia; es una parte integral de ella, el ambiente del que ella nace y en el que cobra su carácter.

La novela no es la única forma de escritura que ha surgido alrededor de la precaria situación en Medellín. Varias obras sociológicas han tratado de descubrir las raíces del problema de la violencia, considerándolo de manera sistemática en un esfuerzo por proponer

${ }^{1}$ Quisiera agradecer a Lidia Santos, cuyo seminario sobre el cosmopolitismo en la literatura hispanoamericana me inspiró a emprender este trabajo, y cuyos consejos y apoyo me ayudaron a terminarlo. También merecen una expresión de gratitud Raúl Verduzco, Héctor Antonio Sánchez y Karla Sánchez, que me ayudaron en su redacción. 
soluciones a la creciente delincuencia de la ciudad y su consiguiente fragmentación (Cabañas 8). Hasta se ha fundado un nuevo campo dedicado al estudio de la violencia: "la violentología” (Walde 222). A pesar de tomar en cuenta la influencia que el ambiente de la ciudad ejerce en el surgimiento del crimen, el análisis sociológico también padece de cierto abstraccionismo. En su intento de trazar causas claras y soluciones evidentes a esta epidemia social, las investigaciones sociológicas asignan cadenas de lógica a un mundo donde tal raciocinio no está siempre presente, y así nos ofrecen una versión simplificada y hasta distorsionada de Medellín.

Lo que proponemos hacer en este trabajo es examinar dos novelas sicarescas, Rosario Tijeras de Jorge Franco y La Virgen de los Sicarios de Fernando Vallejo, para explorar cómo este género literario no sólo va más allá de una explicación de las causas y las consecuencias de la violencia en Medellín, sino que también revela la medida en que la interpretación analítica abarca una visión limitada de la ciudad. Dicho de otra manera, la novela sicaresca no cuestiona nuestra capacidad de entender a fondo el proceso de la violencia, la cadena de acciones que la generan; más bien, niega la existencia de esta cadena. Nos obliga a reconocer la complejidad de Medellín, su carácter emergente y la conexión inextricable entre la ciudad, la violencia y la novela.

No es casual que empleemos la palabra complejidad con referencia a nuestra falta de habilidad para dar algún sentido a la violencia que padece Medellín. Si la novela sicaresca se incluye en la emergencia de una ciudad donde la delincuencia ha rebasado toda comprensión, la idea de “complejidad” es producto de un campo científico en que la tecnología ha rebasado a la teoría. Paul Cilliers sostiene que los avances de los científicos los han inhabilitado para entender a fondo los procesos que impulsan su propia tecnología (1). Gracias sobre todo a los avances de la informática, se han creado sistemas imposibles de entender usando los tradicionales métodos analíticos de la ciencia. La razón por la cual la complejidad elude el estudio analítico es que éste implica el proceso de dividir un sistema y analizarlo parte por parte. Según Cilliers, cualquier esfuerzo por separar los varios elementos que componen un sistema complejo y examinarlos uno por uno distorsiona la red de interacciones que existe entre ellos. Además, el estudio analítico intenta reducir un sistema a una cadena lineal de causas y efectos. En un sistema complejo, sin embargo, un elemento puede influenciarse de manera recursiva y los elementos que se encuentran en la misma vecindad pueden afectarse de manera recíproca. Finalmente, el método analítico presupone que un sistema es producto de un solo elemento, es decir, que tiene un origen fijo. En el caso de un sistema complejo, su carácter no surge de las propiedades de un solo elemento ni de la suma de los atributos de varios, sino de las interacciones que ocurren en el espacio que separa esos elementos. Dicho de otro modo, la complejidad no reside en los componentes de un sistema sino en el área que existe entre ellos. Es por eso que cada elemento posee una comprensión limitada del sistema del cual forma parte (Cilliers 5). Como veremos más adelante, esta noción de conocimiento localizado se puede ver en los personajes de la novela sicaresca, que se esfuerzan inútilmente por entender y describir la violencia que devora la ciudad a su alrededor.

Lo más interesante de la complejidad son sus afinidades con el desconstruccionismo. Para Cilliers, el pensamiento de Jaques Derrida -sobre todo, su modelo de lenguaje- es lo 
que más nos ayuda a comprender los sistemas complejos en general (27). Ambas teorías se enfocan en un fenómeno sin origen que surge de las interacciones no-lineales entre elementos que no tienen presencia en sí. En el centro de este modelo derridiano está la idea de la différance que, según el pensador francés, no es una teoría autónoma ni autosuficiente, sino un fenómeno que emerge de una serie de afinidades fugaces. Él usa la palabra faisceau, o gavilla, para explicarla:

le mot faisceau paraît plus propre à marquer que le rassemblement proposé a la structure d'une intrication, d'un tissage, d'un croisement que laissera repartir les différent fils et les différents linges de sens -ou de force- tout comme il sera prêt à en nouer d'autres. (Différance 42)

Aquí, los paralelos entre la différance y la complejidad son importantes porque nos dan el marco teórico para ver que, en la novela sicaresca, la complejidad se manifiesta al nivel del lenguaje. Como veremos en este trabajo, Rosario Tijeras y La Virgen de los Sicarios no sólo logran retratar la ciudad de Medellín como un sistema complejo sino que, por medio de su narración -por el carácter complejo del lenguaje-, los narradores expresan el conflicto central en ambas obras: el deseo de separarse o alejarse de la ciudad violenta y el sentirse a la vez fascinado por la misma. En el caso de La Virgen de los Sicarios, este vaivén narrativo entre la separación e implicación se expresa en la violencia verbal y la moralidad condenatoria que Fernando usa para apartarse de Medellín. A pesar de su sangriento juego de palabras, él no logra salvarse de la misma culpa que le imputa a la ciudad. Por otro lado, en Rosario Tijeras vemos que el vaivén narrativo transforma el libro en un bildungsroman narrado desde el margen. Al recontar la historia de su amor secreto a Rosario, Antonio crea un personaje que no es sino su nombre. "Rosario Tijeras” es la unión del amor y la muerte, de la palabra y la acción. Cualquier intento de alejarse de ella -y de la violencia que ella encarna- es inútil, porque narrarla es inevitablemente quererla. Al fin y al cabo, esta fatalidad es el enfoque de la novela sicaresca. Nos sumerge en el complejo sistema urbano, contagiándonos de esta atracción a una ciudad mortífera, esta fascinación suicida por un mundo incomprensible.

Medellín, desde Afuera y deSDE ADENTRO

Haciendo referencia (quiéralo o no) a la idea derridiana de la faisceau, Nigel Clark nos dice que la ciudad emerge de las encrucijadas entre las relaciones económicas y culturales de los seres humanos y que el locus urbano sigue evolucionando a medida que atrae y yuxtapone elementos heterogéneos (14). Clark mantiene que la ciudad es un sistema abierto y proteico que interactúa con los espacios geográficos a su alrededor (otras ciudades, zonas verdes) y sirve de escenario para las prácticas humanas nacientes. Inherente a este ambiente de generación y creatividad constante hay cierta inestabilidad que suele manifestarse como violencia. Por consiguiente, habitar una ciudad siempre se asocia con cierto elemento de riesgo, porque el complejo sistema urbano favorece la turbulencia y la estimulación sobre la seguridad y la estabilidad (Clark 15). En esta sección, emplearemos la óptica de la complejidad para comparar las descripciones de Medellín elaboradas desde la perspectiva 
de las ciencias sociales y el retrato que hallamos en La Virgen de los Sicarios y Rosario Tijeras, dos novelas narradas por sujetos que se encuentran dentro de (e involucrados en) esta gavilla urbana.

En muchos de los estudios sobre Medellín se habla de la "génesis violenta” de la ciudad (Jaramillo Arbeláez 31). Reflejando la rápida urbanización de Colombia durante la segunda mitad del siglo xx, la población de Medellín aumentó de 380.000 en 1951 hasta 3 millones en 1993 (Brand 63; Ceballos Melguizo 113). Debido en parte al endeble Estado, casi el sesenta por ciento de la ciudad actual se construyó sin seguir las reglas de planificación urbana del gobierno. Hoy día, estos barrios “piratas” son más grandes que la ciudad formal, tanto en términos de población como de superficie. Surge al punto la noción de Medellín como una ciudad fragmentada. Por un lado, esta fragmentación refiere a la división de la ciudad en comunas y zonas, hecha por el gobierno para mejorar la gestión (Jaramillo Arbeláez 33). Por otro lado, se refiere a la idea de la ciudad colombiana como una "proto-polis", una precaria y embrionaria entidad urbana que, en las palabras de Jacques Aprile-Gniset:

Todavía muestra, tanto en su geografía y morfología como en su sociedad, numerosas huellas de su origen rural y su larga tradición agraria, indicando la fase de transición que está experimentando. [...] Oscilando entre lo arcaico y lo nuevo, no es aún ciudad moderna sino más bien una 'ante-ciudad', un proyecto. (595)

La idea de proto-polis no concuerda con nuestra noción del sistema complejo porque da una imagen lineal del desarrollo urbano. Propone una progresión que empieza con lo rural y termina en el momento en que una zona llega a ser una verdadera ciudad. Este concepto se basa en una oposición entre lo rural y lo urbano, dos categorías que no son exclusivas en realidad sino fluidas e interactivas (Clark 25). Además, la noción de proto-polis supone que la ciudad procede de un origen fijo que no es ella misma. Debemos acordarnos aquí de las palabras de Derrida cuando explica su teoría de la différance, negando que la hipótesis de una proto-entidad pueda aplicarse al lenguaje: “ce qui s’y met précisément en question, c'est la requête d'un commencement de droit, d'un point de départ absolu, d'une responsabilité principielle” (Différance 44-5). Apropiándonos de esta resolución para nuestro estudio, podemos decir que la ciudad no es la suma de una progresión lineal de acciones humanas que traen como resultado la pérdida de cualquier rasgo de lo rural; más bien, es un juego constante que surge de las interacciones que existen entre los seres humanos.

Un aspecto de la fragmentación que sí es pertinente a nuestra interpretación es la relación que existe entre la violencia y la división de la ciudad en espacios sociales cada vez más pequeños y fragmentados. Ahora bien: hay dos maneras de ver dicha relación. La primera pertenece a una visión sociológica de Medellín basada en una cadena de causas y efectos, según la cual la explosión de violencia ha llevado a la descomposición de la antigua vida pública de Medellín:

Con la generalización de diferentes formas y actores de violencia en la ciudad se acentuará una tendencia de repliegue hacia lo privado que ha desvalorizado aún más lo público y le ha asignado mayor importancia a la búsqueda de seguridad en el entorno inmediato al cual se pertenece. El control de territorios cada vez más pequeños por parte de actores armados [...] ha tenido un impacto notable en la fragmentación de los barrios. (Jaramillo Arbeláez 33) 
Por otro lado, podemos ver la fragmentación no como un resultado de la violencia sino como una de sus características inherentes. La violencia, como cualquier otra forma de interacción humana, tiene la potencia para formar una serie de encrucijadas que contribuye al carácter emergente de una ciudad. Aquí, el doble sentido de la palabra "emergencia”, la oscilación entre la idea de surgimiento y la de desgracia, nos muestra hasta qué punto la complejidad se percibe en la violencia. Por ejemplo, en el Medellín de los años ochenta y noventa, organizaciones denarcotraficantes-"bandas de la pesada"-se asociaban con pandillas de adolescentes-"galladas"-y jóvenes asesinos-"sicarios"-. Con la introducción del "basuco" (droga derivada de la cocaína) en barrios pobres, surgieron las pandillas -“chichipatos”-, grupos de jóvenes sin vínculo formal al negocio del narcotráfico. Tras un aumento de violencia, se formaron "milicias populares" en la zonas pobres de la ciudad para combatir la delincuencia. Estas bandas, a su vez, fueron incorporando el discurso de grupos guerrilleros como el Ejército Popular de Liberación y el Movimiento 19 de Abril. Alrededor del año 85, grupos como "Los Capuchos" habían creado una asociación dedicada, a la vez, al crimen organizado y al combate contra la delincuencia. ${ }^{2}$ En última instancia, lo que presenciamos en Medellín es una multitud de organizaciones criminales (algunas situadas a nivel local, otras a nivel nacional e internacional) en interacción dentro del mismo escenario urbano. Y estos grupos no sólo se encuentran en un estado de transformación constante sino que hasta los propios actores de la violencia carecen de identidad fija. Como bien lo expresa Ramiro Ceballos Melguizo:

It could be shown in a wealth of examples that the armed actors in Medellín are more complex and varied than any dichotomy and that various combinations of criminal activities, and simple youthful violence have produced various kinds of actors whose profiles are unstable. (124)

Puede decirse que cualquier acto de violencia en la ciudad de Medellín emerge de un sistema complejo de interacciones humanas que es imposible de entender en su totalidad.

El retrato que Rosario Tijeras y La Virgen de los Sicarios muestran de la delincuencia en Medellín concuerda con la historia que nos proponen los textos sociológicos: la inmigración a la ciudad, el surgimiento de barrios piratas y la emergencia de la violencia. Sin embargo, las novelas se distinguen por cierto desprecio hacia lo popular por parte de sus narradores, un esfuerzo por hacer una clara distinción entre sí mismos y la población de las comunas. En Rosario Tijeras, se cuenta que los padres de Rosario, “como casi todo los de la comuna, bajaron del campo buscando los que todos buscan, y al no encontrar nada se instalaron en la parte alta de la ciudad para dedicarse al rebusque” (14). En La Virgen de los Sicarios, Fernando también nota esta división espacio-cultural, diciendo que "Medellín son dos ciudades: la de abajo, intemporal, en el valle; y la de arriba en las montañas, rodeándola”. La violencia, a su vez, es una fuerza que emana de las comunas: "Es el abrazo de Judas.

\footnotetext{
${ }^{2}$ Toda esta información viene de Ceballos Melguizo (115-22). Para un estudio aún más detallado, véase el capítulo dos de Jaramillo Arbeláez (57-114). Es interesante notar las diferencias de terminología en estas dos obras (por ejemplo, bandas de pesada versus bandas blandas). Esto nos hace aún más claro el carácter proteico de la violencia en Medellín.
} 
Esas barriadas circundantes levantadas sobre las laderas de las montañas son [...] la chispa y leña que mantienen encendido el fogón del matadero” (82).

A pesar del miedo y del desprecio que los "invasores de las montañas” (Franco 39) inspiran en los dos narradores, éstos muestran una fuerte reverencia hacia el otro Medellín que no se atreven a trepar. Tal vez porque sólo se puede observarlo mirando hacia arriba, ambos lo asocian con el cielo. Antonio se siente agradecido con Rosario por haberle acercado “a la otra ciudad, la de lucecitas” (39, también 6), como si éstas fueran estrellas. Por mucho que Fernando odie las comunas, le proporciona a esta metáfora celestial un toque divino cuando nos pregunta: “¿Que cómo sé tanto de las comunas sin haber subido? Hombre, muy fácil, como saben los teólogos de Dios sin haberlo visto” (86). Es en esta ambivalencia en las descripciones del otro Medellín, en el querer separarse de y a la vez tenerle cierta fascinación, cuando vemos los primeros rasgos de la différance que exploraremos en la siguiente sección.

Aunque puede decirse que los estudios de sociología como el de Ceballos Melguizo presentan un Medellín complejo, una red de interacciones de las cuales surge el fenómeno de la violencia, siempre hay cierta distancia entre el sujeto y la ciudad. Paul Cilliers nos recuerda que a veces distinguir entre un sistema complejo y un sistema complicado pero comprensible, depende de la perspectiva, de la distancia entre el sistema y el sujeto que lo observa (3). Por lo tanto, la situación de Medellín, vista desde la óptica sociológica, parece reducirse a una función casi matemática: la urbanización rápida y el Estado débil se suman a la marginación de grupos pobres, lo cual conduce a la violencia. El texto sociológico hace divisiones analíticas que simplemente no existen en la novela sicaresca, y aun cuando se problematizan estas divisiones, no se muestra la relación recíproca entre sujeto y ciudad, la falta de cualquier barrera entre los dos, que caracteriza a la novela sicaresca. Dicho de otra manera, mientras Jaramillo Arbeláez habla de "la imposibilidad de aplicar a nuestra realidad la fórmula que separa de manera tajante a víctimas y victimarios” (242), Fernando declara que "aquí todo el que existe es culpable" (83).

En las novelas sicarescas que aquí estudiamos, el narrador está inextricablemente involucrado en la complejidad de Medellín, lo cual le imposibilita tener un punto de vista alejado y objetivo o saber dónde se ubica la división entre la ciudad y él mismo. "Yo no inventé esta realidad”, nos dice Fernando, "es ella la que me está inventando a mí” (76). Este presentimiento no puede sino recordarnos las palabras de Nigel Clark acerca de la percepción de un individuo cuando él mismo es un elemento de un sistema complejo: “at the concrete, lived level we know only what is local or proximote, only what is adjacent in the networks which we create and which recreate us” (20). En suma, Rosario Tijeras y La Virgen de los Sicarios se diferencian de cualquier estudio sobre Medellín porque dan una visión compleja de la ciudad por medio de un personaje-narrador que intenta pintar una imagen de ella desde lejos pero que, al formar parte del mismo sistema complejo, da al lector una narración impregnada de -y hasta creada por- la ciudad violenta a su alrededor.

LA DIFFÉRANCE: NARRACIÓN Y SEPARACIÓN

Sería un error concluir que la tensión que acabamos de mencionar es producto de un narrador que se encuentra atrapado entre dos extremos: la separación de y la implicación 
en la violencia de Medellín. Reducirla a tal dilema sólo asignaría el vaivén que vemos en el discurso narrativo de ambas novelas al narrador mismo, como si su punto de vista se moviera u oscilara constantemente entre estos dos extremos. En realidad, la perspectiva del narrador es el único elemento invariable en ambos libros. Las narraciones de Antonio y de Fernando siempre se limitan a lo que está a su alrededor inmediato, y desde este punto de vista inalterable observan un mundo donde todo está en flujo, donde la ciudad de Medellín emerge de una serie innumerable de interacciones entre los elementos individuales de un solo sistema y entre los varios sistemas que operan dentro de las novelas, como la ciudad, la violencia y el lenguaje. Por consiguiente, lo que queremos explorar aquí no es el movimiento inexistente de la perspectiva narrativa de Antonio y Fernando, sino la manera en que éstos logran participar en la formación de la red urbana de Medellín a pesar de, repetimos, la estabilidad de sus puntos de vista.

Según Jacques Derrida, hay una razón por la cual toda oposición que sea supuestamente irreducible (como la de separación/implicación que arriba mencionamos) siempre termina calificada como una "ficción teórica" (Différance 58), y tiene que ver con la teoría del lenguaje que él propone. Derrida sostiene que la unidad básica de un idioma no es el signo, que incorpora el significado y el significante, sino que un idioma consiste únicamente en significantes. Por lo tanto, el lenguaje sólo existe en relación consigo mismo, es decir, constituye su único antecedente. Éste es el primer aspecto de la différance: una palabra sólo se conserva en la medida en que se diferencia de las palabras a su alrededor. Y dado que una palabra sólo existe en contraste con otras, el segundo aspecto de este concepto es la manera en que un vocablo difiere su propia definición, pasándola a las palabras de su contorno. Así surge el juego de palabras entre la “diferencia” y la “deferencia”. De este modo, el lenguaje es un sistema donde cada significante deja una huella (trace) en otro o, con palabras de Derrida: “ces différences sont elles-mêmes des effets” (Différance 50).

Hay también una dimensión temporal e histórica presente en la différance -“diferir” en el sentido de aplazar o posponer-que se relaciona con nuestra crítica de la proto-polis. Si el lenguaje es una dinámica serie de diferencias y deferencias, los sentidos que él genera no tienen un origen fuera del sistema lingüístico. Es en este contexto donde Derrida dice que la huella, o trace, se vuelve su propio origen, o "l'origine de l'origine” (Grammatologie 90). Una significación tampoco llegará a independizarse del sistema lingüístico, a realizarse totalmente en el presente. Y dado que la ciudad es un sistema tan complejo como el lenguaje y comparte las mismas características de la différance, puede decirse que ésta no es el resultado de una progresión lineal y finita desde lo rural hasta lo urbano: es una entidad emergente cuyo carácter no depende de una noción a priori de la ciudad sino de una historia de interacciones que han creado su situación actual. En términos derridianos:

Si les mots et les concepts ne prennent sens que dans des enchaînements de différance, on ne peut justifier son langage, et le choix des termes, qu'à l'intérieur d'une topique et d'une stratégie historique. La justification ne peu donc jamais être absolue et définitive. Elle répond à un état des forces et traduit un calcul historique. (Grammatologie 102)

Es aquí donde vemos el fuerte vínculo entre la desconstrucción, la teoría de la complejidad y la ciudad. Tanto Derrida como Cilliers y Clark describen entidades que emergen de la faisceau 
de interacción: redes fluidas de elementos, donde no existe una jerarquía vertical sino una serie de asociaciones no-lineales por medio de las cuales un elemento llega a afectar a todos: un sistema complejo que no tiene origen ni destino y que siempre guarda cierta memoria de su historia a pesar de nunca encontrarse en un estado presente o realizado.

Si volvemos a explorar el discurso narrativo de Rosario Tijeras y La virgen de los sicarios, ahora desde la perspectiva de la différance lingüística, podemos ver el vaivén del narrador -su deseo de diferenciarse del entorno urbano y a la vez sentirse desesperadamente involucrado en el mismo- como producto del acto de narrar, del lenguaje mismo. Por medio de su narración, Fernando y Antonio ponen en movimiento un proceso de diferenciamiento y deferenciamiento del cual brota la ciudad de Medellín. Tras crear esa realidad literaria en su exterior, la propia narración transforma a los narradores mismos -así la ironía cuando Fernando dice que la realidad de Medellín lo está creando a él-. Cualquier intento de alejarse de Medellín sólo lo pone más cerca. Dentro de este contexto, la descripción que Antonio nos proporciona de la ciudad cobra otro sentido, mostrando la reciprocidad entre su narración y la ciudad que él retrata: "El que se va vuelve, el que reniega se retracta, el que la insulta se disculpa y el que la arremete las paga” (95).

Vale la pena aquí mencionar el flâneur por los paralelos entre esta figura del París decimonónico y el narrador de la novela sicaresca. Ambos surgen tras el crecimiento repentino e inquietante de una ciudad. A pesar de una epidemia de cólera durante los años 1830, la población de París aumentó de 500.000 a un millón en sólo cincuenta años (Ferguson 30). Es durante esta época que advertimos el surgimiento del hombre que ve la muchedumbre de la ciudad como un espectáculo. Es un alejado observador de la vida humana, un científico que va grabando la geografía "botánica” del ambiente urbano (Benjamin 62; Clark 13), un poeta anónimo que repuebla la soledad de su condición moderna con las caras desconocidas de su entorno. En su libro de poemas en prosa Spleen de Paris, dice Charles Baudelaire: "Multitude, solitude: termes égaux et convertible par le poëte actif et fécond. Qui ne sait pas peupler sa solitude, ne sait pas non plus être seul dans une foule affairée” (34).

Si la característica esencial del flâneur es la habilidad de estar en la muchedumbre y pertenecer a ella (Tester 3), no podemos equiparar a Antonio y a Fernando con este personaje porque lo que los define es justamente su conexión compleja -y, por lo tanto, recíproca- con Medellín. No se puede negar que exista una separación en las dos novelas entre el narrador y la ciudad, ni que el narrador recuerde el anonimato del París moderno (por ejemplo, Fernando hace hincapié en ser “el hombre invisible” [116]). No obstante, no debemos hacer un paralelo entre estos personajes sicarescos y el flâneur, porque mientras el realismo de siglo XIX se caracteriza por un narrador alejado que puede ver y describir sin dificultad el complicado tejido de relaciones humanas que forman la ciudad a su alrededor, el hecho de que los narradores de Rosario Tijeras y La virgen de los sicarios son elementos de este complejo sistema urbano les impide alcanzar a una visión totalizadora de la ciudad. Fernando parece estar muy conciente de esto cuando nos dice: "Yo sé más de Medellín que Balzac de París, yo no lo invento: me estoy muriendo con él” (41).

Tal vez es tentador calificar al narrador de La virgen de los sicarios como un escritor flâneur porque él siempre intenta separarse de la violencia de Medellín a través de su lenguaje. Bautizándose el "gramático ilustre”, Fernando anuncia al lector que "todo el 
problema de Colombia es una cuestión de semántica” (48). Cuando Alexis mata al hombre que los ha llamado "maricas”, Fernando nota que no es por la "palabra en sí” que su novio le ha pegado un tiro, sino por "su carga de odio" (42). Y tras exponer las connotaciones negativas del apellido de un cardenal que ha mandado matar a Alexis, Fernando nos dice: "No es culpa mía, es cuestión de semántica” (70). Esta última frase demuestra la ambivalencia del narrador sobre su propio papel en la violencia de la novela. Casi todos los homicidios de Alexis observados por Fernando van precedidos por algún comentario de este último. Si Alexis despacha al vecino hippie de Fernando, es porque éste se ha quejado del alto volumen con que el "metalero condenado" escucha su música (25). En este contexto, si el vecino es “condenado", lo es por el narrador.

Todas las víctimas de esta pareja mueren de la misma manera: Fernando los apunta con un comentario y Alexis los asesina con una bala. Aunque Fernando a veces se arrepienta de haber hablado, nunca se echa la culpa a sí mismo: "Ni nadie, nadie, nadie me ha visto hasta ahora disparar" (63). En un caso, él hasta se indigna cuando oye por la radio que dos inocentes han sido asesinados por una pareja de sicarios. “¿Yo un presunto ‘sicario’?”, contesta. “¡Desgraciados! Yo soy un presunto gramático!” (44). En realidad, el lenguaje con el que Fernando sanciona a estas personas y con el que maneja las acciones de Alexis es el mismo castellano que él usa para diferenciarse de su amante sicario. Mientras Fernando se dice un gramático, mantiene que Alexis "[n]o habla español, habla en argot o jerga" (23). Sin embargo, es evidente que la distinción que hace entre español y jerga, inocente y culpable, consiste en una cuestionable diferencia de semántica y una consciente deferencia de culpa.

Tras una descripción de las balas benditas que los sicarios emplean en sus asesinatos, Fernando cita una parte de la canción "La gota fría”, siguiéndola con una explicación de la letra: “'Me lleva a mí o me lo llevo pa’ que se acabe la vaina’. Lo cual, traducido al cristiano, quiere decir que me mata o lo mato porque los dos, con tanto odio, no cabemos sobre este estrecho planeta" (64). Aunque parezca casual aquí su uso de la palabra "cristiano" como sinónimo de la lengua española, nos muestra hasta qué punto el presumido refinamiento gramático de Fernando está ligado con su sentido de superioridad moral y fervor religioso. A primera vista, pensar el narrador de La virgen de los sicarios como una persona moral -e incluso beata- parece una idea ridícula dada la ambigüedad lingüística -el juego entre separación e implicación- que caracteriza su narración. Hasta parece que Fernando se condena a sí mismo y a su propio libro mientras condena su país. En una proclamación de carácter bíblico, nos dice que "Ni en Sodoma ni en Gomora ni en Medellín ni en Colombia hay inocentes” (83). Sin embargo, es precisamente en el tono apocalíptico de esta frase donde encuentra su integridad. Aquí no vemos ninguna inmoralidad ni amoralidad. Fernando traza una línea tajante entre la inocencia y la culpabilidad y ubica a todos del lado de los condenados. Es esta creencia profunda y dogmática en la culpabilidad de todos los seres humanos de Medellín la que motiva su "cotidiana obra de caridad” (67). Si Fernando ve a Alexis como el "Ángel Exterminador que había descendido sobre Medellín a acabar con su raza perversa” (55), se ve a sí mismo como la fuerza moral, el supervisor justiciero que dirige al sicario en este trabajo.

Aunque el fervor religioso que motiva su matanza nos recuerda al Dios vengador del Antiguo Testamento, no debemos concluir que Fernando se cree un Dios. En cambio, tenemos 
que reconocer que a lo largo de la mayor parte del libro, él parece creer en una moralidad superior, en la cual se basa su visión cínica de la situación colombiana. La disolución, desde luego, de esta creencia, el cuestionamiento de la existencia de Dios, es una crisis central de La virgen de los sicarios. Desde el comienzo del libro, Fernando va de una iglesia a otra, hasta se jacta de conocer las ciento cincuenta iglesias de Medellín (53). Pero esta devoción se acaba hacia el final de la novela, cuando él y Alexis se topan con un perro moribundo en la calle. Aunque es evidente que el animal va a morir, Alexis se niega a darle el tiro de gracia. "Tienes que ser" (77), le dice a su amante. Éste, que acaba de declarar que los animales son su prójimo y el amor de su vida (75), vacila un momento ante la decisión:

¿Habría tratado [el perro] de volver acaso, herido, a su casa? ¿Pero es que tendría casa? Sólo Dios sabrá, él que es culpable de estas infamias: Él, con mayúscula que se suele usar para el Ser más monstruoso y cobarde, que mata y atropella por mano ajena, por la mano del hombre, su juguete, su sicario. (77)

En esta profanación, Fernando no sólo describe la situación en que Dios lo ha puesto a él, sino también aquella en la que él ha puesto a Alexis. No sólo acusa a Dios de ser cobarde, se condena a sí mismo. Cuando Fernando por fin mata al perro, la distancia que él ha puesto entre sí mismo y la humanidad se esfuma, y la fe y la moralidad religiosa a las cuales antes se adhería dejan de existir: "soy parte de la porquería humana”, nos dice. "Dios no existe y si existe es la gran gonorrea” (78). Si recordamos el hecho de que Fernando narra toda la trama del libro retrospectivamente, cuando ya se encuentra en la estación de autobuses, podemos ver que el tono de resignación total que domina el discurso del libro nace justo cuando él mata al perro. Es el momento exacto en que Fernando se vuelve un "muerto vivo" (76), cuando el narrador que antes se diferenciaba de su ambiente urbano se convierte en otro elemento más del sistema complejo de Medellín.

El mismo juego de separase e involucrarse -el vaivén de la différance- predomina en Rosario Tijeras, pero se manifiesta de manera distinta. Puede decirse que la novela es un bildungsroman que gira en torno a un protagonista inesperado. Aunque Antonio narra la historia de cómo Rosario saca a Emilio y a él de "esa adolescencia que ya jóvenes nos resistíamos a abandonar" (88), él siempre se pinta como un simple "compinche”. Mientras "Emilio conseguía las mujeres, la plata, el trago, las emociones de la vida”, Antonio "trataba angustiosamente de hacerle frente a ese modo de vida que era imperativo en los jóvenes" (87). Sólo Emilio cumple con la trayectoria tradicional del bildungsroman: es un niño burgués que pasa por una etapa liminal, donde conoce una mujer al margen de la sociedad que le enseña ese "lado oscuro" (29) de la vida y que, al fin y al cabo, logra escapar a esa vida limítrofe y hacerse "gente decente" (152). Pero, a pesar de cumplir todos los requisitos que deben ponerlo al centro de la obra, no es Emilio sino Antonio -el acompañante que confiesa ser "el último de la fila” (165)- el protagonista.

En La virgen de los sicarios, es muy claro que Fernando es el centro de la novela y que juega un papel directo en la violencia usando sus palabras para marcar a la siguiente víctima de su amante. En cambio, la influencia de la voz narrativa de Antonio es más indirecta porque Rosario y sus actos violentos constituyen el enfoque de la obra. Igual que el libro de Vallejo, Rosario Tijeras surge de una narración retrospectiva. La trama gira en torno 
a un solo acontecimiento, la noche que Antonio y Rosario pasaran juntos. A la vez que la memoria del narrador va acercándose a este evento, un retrato nítido de Rosario Tijeras se nos va revelando: su niñez en la comunas, su venganza con unas tijeras del hombre que la violó y sus relaciones con los sicarios más notorios y los narcotraficantes más poderosos de Medellín. Vemos crecer la obsesión que Antonio tiene por ella, sobre todo cuando la cuida tras la muerte de su hermano y la partida de su novio. Esta fascinación llega a su colmo cuando los dos deciden a escaparse de Medellín e irse a Miami. Pero antes de que puedan emprender el viaje, Antonio recibe una llamada del hospital, notificándole que ha llegado una mujer casi muerta a balazos, cuya única posesión es un pedacito de papel con este número telefónico. Él llega al hospital, y mientras espera que su amiga salga viva de una cirugía, va recordando los sucesos que los han llevado hasta ese momento. Al final de la novela, Rosario no se salva, pero Antonio, por medio del inventario de recuerdos que realiza durante la noche aparentemente eterna en la sala de espera del hospital, logra revivirla de alguna manera, asignando una narración literaria tanto a la vida de Rosario, como a la violencia que la ha definido.

Rosario Tijeras nos muestra el carácter emergente del personaje en la novela sicaresca, la relación íntima que éste tiene con la complejidad del lenguaje y hasta con las palabras que componen su propio nombre. Al comienzo de su narración, Antonio nos dice de su amiga: “Tijeras no era su nombre, sino más bien su historia” (8). Ella siempre se caracteriza por un elemento de unión, la imposibilidad de separarla de su apodo, de distinguir entre sus acciones y su identidad. Antonio la retrata como una fuerza suicida, diciendo que ella y la muerte son inextricables: "No se sabía quién encarnaba a quién pero eran una [idea] sola” (92). Puede decirse que Rosario es un ejemplo vivo de la teoría derridiana del lenguaje: un ser cuyo único origen es su propio nombre. La última frase del libro demuestra mejor cómo toda la novela, toda la historia de violencia y amor, se reduce a un par de palabras, del cual surge esta femme fatale: "eso es todo: Rosario Tijeras" (165).

Antonio es el centro de Rosario Tijeras por su papel de narrador, porque trabaja en y con las palabras. Si Rosario se encapsula en un nombre, enunciarla es crearla; es dar cuerpo a la fuerza "fatalmente divina" que sincroniza el beso con el balazo (35) y hace confundir "el dolor del amor con el de la muerte" (5). De algún modo, esta última cita describe la obsesión que motiva la narración de Antonio. Mientras el narrador de La virgen de los sicarios se domina por un sentido de moralidad, manejando su discurso con toda la precisión de un punto de mira, en ningún momento puede Antonio controlar a la mujer, el enfoque de su obsesión, que emerge de su narrativa. Cada vez que él menciona el nombre de Rosario, aparece una figura de la que él quiere huir pero a quien no puede dejar. Él está consciente de esta paradoja cuando se despide de Rosario por última vez: "ese adiós definitivo tampoco fue el último, otra vez he vuelto” (105).

Es en esta noción de "amor suicida” (Franco 88) que los narradores de Rosario Tijeras y La virgen de los sicarios más se parecen. Sus discursos son la unión del horror y la fascinación que ocurre ante la violencia de la ciudad. Tanto Antonio como Fernando preparan huidas de Medellín que nunca llegan a realizarse, y ambos vuelven a perderse en este complejo sistema urbano, a internarse otra vez en "el laberinto de los callejones y de los odios, tratando de desentrañar lo inextricable” (Vallejo 58). 


\section{CONCLUSIÓN}

Tanto las obras sociológicas sobre Medellín como las novelas sicarescas que hemos explorado en este trabajo son interpretaciones de una situación real; son intentos de encarnar en prosa la enigmática violencia de la ciudad. Cada una de estas formas de escritura padece de ciertas limitaciones. Por una parte, la sociología, en su esfuerzo por hacer comprensible la realidad de Medellín, emplea un proceso analítico que no consigue representar la complejidad inherente de la ciudad y que inevitablemente termina distorsionando la misma. Por otra parte, la novela sicaresca nos sumerge en dicha complejidad a tal punto que nos causa un sentimiento de desorientación, no sólo la sensación de ser incapaces de entender las fuerzas abstractas que motivan los actos violentos que vemos, sino también el inquietante presentimiento de que estas fuerzas ni siquiera existen.

Por medio de una narrativa de primera persona, La virgen de los sicarios y Rosario Tijeras nos muestran la visión limitada que uno posee cuando se encuentra dentro del complejo sistema urbano, cuando uno no es sino un elemento en una proteica red de interacciones humanas. Desde un punto de vista fijo, Fernando y Antonio describen el ambiente fluido de su contorno, empleando un lenguaje que, por su naturaleza compleja, revela la relación recíproca que existe en la novela sicaresca entre el narrador y la ciudad de Medellín. De esta reciprocidad emerge una tensión, el deseo del narrador de separarse -y hasta huir- de la ciudad y, al mismo tiempo, estar totalmente captado por ella, incapaz de dejarla. Para Fernando, es imposible mantener la distancia que su sentimiento de superioridad gramática y moral le da, mientras que Antonio nunca tiene la fuerza para abandonar a la mujer que es victimaria y a la vez víctima de la violencia de Medellín.

En última instancia, no debemos concluir que las distintas visiones de Medellín que ofrecen el estudio sociológico y la literatura sicaresca se contradicen, que uno revela las flaquezas de la otra. Más bien, son perspectivas complementarias sobre el fenómeno de la violencia urbana. Mientras la sociología se enfoca en la búsqueda de causas, consecuencias y soluciones concretas, novelas como Rosario Tijeras y La virgen de los sicarios nos enseñan los modos de interpretación que se encuentran más allá de las fronteras del pensamiento analítico y la relación problemática que uno comparte con su contorno. Sobre todo, estas obras dejan ver que el lenguaje que usamos para interactuar con nuestro ambiente es tanto evaluativo como constitutivo de este ambiente (Benhabib 203). Por medio del carácter complejo de la palabra, un narrador no sólo describe un fenómeno externo, como la vida de un sicario perdido en la violencia de Medellín, sino que puede definirlo -y hasta ayudar a formarlo- también.

BiBLIOGRAFÍA

Aprile-Ginset, Jacques. La ciudad colombiana: siglo XIX y siglo XX. Bogotá: Banco Popular, 1992.

Baudelaire, Charles. Petits poëms en prose (Le spleen de Paris). París: Société des Belles Lettres, 1934.

Bass, Alan.“'Literature’/Literature”. Jaques Derrida: Critical Thought. Ian Maclachlan, ed. Hampshire: Ashgate, 2004. 14-23. 
Benhabib, Seyla. Situating the Self: Gender, Community, and Postmodernism in Contemporary Ethics. Cambridge: Polity Press, 1992.

Benjamin, Walter. Charles Baudelaire: A Lyric Poet in the Era of High Capitalism. Harry Zohn, trad. Londres: Verso, 1983.

Brand, Peter. "Ecologism and Urban Space: Nature, Urbanisation and City Planning in Medellín, Colombia”. Planning Practices and Research 10/1 (1995): 55-66.

Cardona López, José. "Literatura y narcotráfico: Laura Restrepo, Fernando Vallejo, Darío Jaramillo Agudelo”. Literatura y cultura: narrativa colombiana del siglo XX. María Mercedes Jaramillo, Betty Osorio y Ángela Inés Robledo, eds. Tomo 2. Bogotá: Ministerio de Cultura: 2000. 378-406.

Cabañas, Miguel. "El sicario en su alegoría: la ficcionalización de la violencia en la novela colombiana de finales del siglo XX”. Taller de Letras 31 (2002): 7-29.

Ceballos Melguizo, Ramiro. "The Evolution of Armed Conflict in Medellín: An Analysis of the Major Actors”. Colombia: The Forgotten War. Francine Cronshaw, trad. Número especial de Latin American Perspectives 28/1 (2001): 110-31.

Cilliers, Paul. Complexity and Postmodernism: Understanding Complex Systems. Londres: Routledge, 1998.

Clark, Nigel. “'Botanizing on the Asphalt’? The Complex Life of Cosmopolitan Bodies”. Body \& Society 6/3-4 (2000): 12-33.

Derrida, Jacques. “Différance”. Théorie d'ensemble. Michel Foucault, et al. Collection “Tel Quel”. París: Éditions du Seuil, 1968. 41-66.

De la grammatologie. París: Éditions de Minuit, 1967.

Ferguson, Priscilla Parkhurst. “The Flâneur: from Spectator to Representation”. The Flâneur. Keith Tester, ed. Londres: Routledge, 1994.

Fernández L’Hoeste, Héctor D. “La Virgen de los Sicarios o las visiones dantescas de Fernando Vallejo”. Hispania 83/4 (2000): 757-67.

Franco, Jean. The Decline and Fall of the Lettered City. Cambridge: Harvard UP, 2002.

Franco, Jorge. Rosario Tijeras. [1999] $1^{\text {a }}$ edición norteamericana. Nueva York: Siete Cuentos Editorial, 2004.

Jaramillo, María Mercedes, Betty Osorio y Ángela Inés Robledo. Literatura y cultura: narrativa colombiana del siglo XX. 3 tomos. Bogotá: Ministerio de Cultura: 2000. 378-406.

Jaramillo Arbeláez, Ana María, Ramiro de J. Ceballos Melguizo y Marta Inés Villa Martínez. En la encrucijada: conflicto y cultura política en el Medellín de los noventa. Medellín: Secretaria de Gobierno Municipal; Bogotá: Programa para la Reinserción, 1998.

Lander, María Fernanda. “The Intellectual’s Criminal Discourse in Our Lady of the Assasins”. Discourse 25/3 (2003): 76-89.

Maclachlan, Ian, ed. Jaques Derrida: Critical Thought. Hampshire: Ashgate, 2004.

Shields, Rob. "Fancy Footwork: Walter Benjamin's Notes on Flânerie”. The Flâneur. Keith Tester, ed. Londres: Routledge, 1994.

Tester, Keith, ed. The Flâneur. Londres: Routledge, 1994.

Vallejo, Fernando. La virgen de los sicarios. [1994] 2a edición. Bogotá: Alfaguara, 1998. 
Walde, Erna von der. "La sicaresca colombiana: Narrar la violencia en América Latina”. Nueva Sociedad 170 (2000): 222-27.

Watson, Sophie y Katherine Gibson, eds. Postmodern Cities and Spaces. Oxford: Blackwell, 1995. 